Makurin A. A., Doctoral Student Kharkiv State University of Food Technology and Trade Kharkiv, Ukraine

DOI: https://doi.org/10.30525/978-9934-26-145-9-22

\title{
MEASURING THE VALUE OF DIGITAL ASSETS FOR ACCOUNTING PURPOSES
}

Fair value in the system of the International Financial Reporting Standard (IFRS) is devoted to a separate, rather specific standard IFRS 13 "Fair Value Measurement", which defines that fair value is the price that can be obtained for the sale of a certain asset in a purchase/sale operation on the date of such operation. The main condition is that it is necessary to declare the price as openly as possible and compare the declared price with the price of an identical product from open sources of information [1]. Therefore, the fair value is based on determining the market price and does not take into account the specifics of the object being sold. For example, when comparing the cost of 1 gramme of gold and 1 litre of water, there is no doubt that the cost of precious metal (gold) will be higher. However, if the market conditions are significantly changed and such objects are compared in the conditions of a blazing hot Sahara Desert, it can be affirmed that a person would choose 1 litre of drinking water, instead of 1 gramme of gold. Therefore, it is important to determine the open market information and the conditions in which a particular resource asset is evaluated. The purpose of a fair valuation is to apply fair value in both conditions that should be considered common in the market. But it is important to understand what exactly are the usual conditions of the cryptocurrency market, for its implementation, acquisition, or exchange [2]. Considering fair value in terms of the accounting valuation category, it can be argued that the value of an asset is equal to the value of liabilities at a certain date and time. Because economists understand that USD 100 yesterday and today, and three days later are different USD 100, not at par value, but in practical (real). 
Market value - the value to which the seller agrees when selling an asset and the buyer when receiving such an asset, who is willing to pay the specified amount deliberately and without compulsion [3]. The market value and can only be determined for such property that can be transferred from one party to another. To use the market value of an asset valuation, there are three main calculation approaches. The first approach is based on market research. It is based on comparing prices for products that are identical or similar, but are represented on the market by different buyers. The second approach is called incomebased, which is based on the fact that the received property (asset) in the future could bring the owner a certain income from its maintenance. The third approach is called cost-based, based on determining the cost of creating such property.

Therefore, further research may be related to the definition of digital cost, which is adaptive exclusively for digital assets. For example, the market value is an estimate of such a digital asset, a certain crypto coin costs, for example, UAH 100, the market price for it is UAH 150, and the cost of its production at the moment is UAH 120. The sale of such a coin would bring UAH 30 of income (150-120). However, the situation on the crypto coin market is constantly changing and it is appropriate to use market valuation only for a specific asset at a certain time, but it is impossible to use the first and second approaches. Since the change in the conditions for creating a new crypto coin, due to the increase in the cost of electricity in Ukraine increases the prime cost, which reduces income, and whether it will be profitable in the market for an individual or a legal entity to purchase such a coin on a Ukrainian or foreign crypto exchange that was created (extracted) in Portugal, provided that electricity in that country is cheaper than in Ukraine.

According to the Ukrainian national valuation standards, there are the following main types of value (the value can be measured and expressed in the amount of cash):

- market value - the cost of purchasing a particular asset at a reasonable price that suits the buyer; 
- present value - the value of an asset at a specific date and time of its valuation. Usually, the actual price valid on a specific date is used;

- liquidation value - the value of alienation of an object, provided that there is a certain period of operation of the object until the moment of disposal and write-off.

This variety is adaptive to objects that have been in operation and are represented on the secondary property market; - reproduction cost - the current amount of costs for creating such an asset at this particular time, taking into account current conditions; - special value - calculation of the value of an asset based on the market value with the addition of the seller's premium; - estimated cost - the cost determined by the established algorithm and depends on the input data involved in the calculation.

For the purpose of personal income tax, the total monthly (annual) taxable income of the taxpayer includes passive income, which includes income received in the form of dividends. Taking into account the above, for certain operations with cryptocurrencies where the attribute value is used, the method of determining it is proposed as follows:

$$
A V=E B^{*}(1-T)-S * A V,
$$

where: AV - attribute value;

EB - income from the sale of a digital asset on a specific date;

$\mathrm{T}$ - tax rate;

$\mathrm{S}$ - the cost of the received digital asset in the past.

An example of calculating the attribute value for the Bitcoin Cash coin for reporting during additional evaluation is presented below. First, it is necessary to define the initial data. Thus, the income from depositing a digital asset on a certain date is USD 254 or UAH 7,112 (as of 06.11.2020). The tax rate is 5\%. The cost of the received digital asset in the past - USD 220 or UAH 6,160 (as of 05.10.2020). The attribute value to reflect the additional valuation in the financial statements is UAH 596.4. The main problems are related to accounting for transactions with cryptocurrencies, crypto assets, crypto coins, and digital assets - when they are used during changes 
and act as a medium of exchange. It is appropriate to consider the accounting of cryptocurrency exchange operations from two sides. The first side is an exchange for similar assets. That is, when cryptocurrency is exchanged for cryptocurrency (Bitcoin - Bitcoin Cash; Ethereum - XRP). An exchange for non-similar assets is considered an exchange of cryptocurrency for other assets, for example, stablecoins (digital gold, digital oil, digital dollar (Tether), litecoins.

For example, the exchange of Bitcoin Cash - Tether; Ethereum WMZ. According to Part 2 of Article 715 of the Civil Code [4] and Part 2 of Article 293 of the Economic Code [4], the main participants in the contract (parties) are two sellers and two buyers at the same time. Since the first seller is the seller of a particular product and declares its value, and the other acts as a buyer who agrees with the declared value, but instead of money provides another product and declares such a value that satisfies him as the seller of the second product (buyer of first product) and another person of the buyer of the second product (seller of the first product). As soon as the property (goods) reaches the buyer, property rights are immediately transferred and counterclaims are automatically credited. Special attention should be paid to the date of transfer/receipt of the goods when performing such a barter operation. Since it is the final operation that closes the obligations under the contract. The contract mainly specifies the value of the asset (goods, property), taking into account the fair value of barter. However, if it is not possible to reliably provide a value assessment of the alienation of property (digital assets), it is proposed to use the attribute value. As for exchange operations for non-similar assets, it is necessary to reflect two operations in accounting [5]. The first transaction reflects the recognition of an asset and liabilities, and the second - an increase in the value of such an asset by the amount of a monetary supplement for it and the recognition of accounts receivable formed as a result of a sale transaction. After that, in the accounting of the two parties to the agreement, it is appropriate to carry out and reflect the offset of counter-debts. 


\section{References:}

1. Han X., Yuan Y., Wang F.Y. A blockchain-based framework for Central Bank digital currency. IEEE International Conference on Service Operations and Logistics and Informatics (SOLI) (Zhengzhou, October 11-13, 2019). Zhengzhou, 2019. P. 263-268.

2. Wang M., Han M., Huang W. Debt and stock price crash risk in weak information environment. Finance Research Letters. 2019. Vol. 33(C). P. 242-248.

3. Svitselska V.V. (2015) Spravedlyva vartist u konteksti MSFZ 13 «Otsinka za spravedlyvoiu vartistiu» [Fair value in the context of IFRS 13 «Fair Value Measurement»]. Visnyk ZhDTU: Ekonomika, upravlinnia ta administruvannia, no. 1(71), pp. 48-55.

4. Tarasova T., Usatenko O., Makurin A., Ivanenko V., Cherchata A. (2020) Accounting and features of mathematical modeling of the system to forecast cryptocurrency exchange rate. Accounting, no. 6(3), pp. 357-364.

5. The European group of valuers' associations. european valuation standards. URL: https://www.tegova.org/data/ bin/a5738793c0c61b_EVS_2016.pdf (accessed 21 March 2021). 